\title{
Urinary beta-aminoisobutyric acid excretion in thalassaemia
}

\author{
PH. FESSAS, A. KONIAVITIS, AND P. M. ZEIS \\ From the Haematology Section and Laboratory, Alexandra Hospital, and the Children's \\ Hospital 'Aglaia Kyriakou', Athens, Greece
}

SYNOPSIS The quantity of beta-aminoisobutyric acid (BAIB) excreted in the urine of patients withก an intact spleen suffering from thalassaemia major appears to be proportional to the number of the circulating normoblasts and inversely proportional to the haemoglobin level.

After splenectomy only minute amounts of BAIB are excreted. Transfusion constantly, buto temporarily, reduces urinary excretion of beta-aminoisobutyric acid. Other anaemic but non- thalassaemic patients may excrete low levels.

Beta-aminoisobutyric acid (BAIB) is considered to be a product of the catabolism of thymine and valine. It is not found in the urine of normal individuals but may be excreted as a hereditary trait; this is fairly common in orientals but infrequent in populations of Caucasian descent. The excretion of BAIB, an acquired condition, is always associated with extensive cellular breakdown, such as may occur in leukaemia, carcinoma, following radiation, and after operations; in these conditions thymine is the more likely source of BAIB (Sutton, 1960).

Hillcoat (1960) reported the presence of large amounts of BAIB in the urine of three patients with thalassaemia major with intact spleens. (In these the levels of urinary BAIB remained constant over long periods of time, irrespective of transfusional therapy, infections, or diet.) Two similar patients, whose spleen had been removed, excreted only minute amounts of BAIB or none at all. In one patient the high level of excretion dropped to a negligible quantity soon after splenectomy (Hillcoat, 1962). Thus a clear-cut relationship between the excretion of BAIB and the presence of the spleen was established. To the best of our knowledge there are no other reports on BAIB in thalassaemia.

In this study an attempt is made to correlate the excretion of BAIB with the haematological status of patients with thalassaemia major; other anaemic patients have been included for control purposes.

\section{MATERIAL AND METHODS}

The eight groups of individuals examined are shown in Table I. Twenty-four-hour urine samples were tested in every case; plastic urine collectors were applied to young Received for publication 22 July 1968. infants. Patients undergoing transfusion therapy received $20 \mathrm{ml}$ of whole blood per kilogram of body weight ande were tested the day before and on the second, eighth, 6 fifteenth, and thirtieth days after transfusion.

A complete haematological examination was performed on every occasion using routine methods. The normoblasts per $\mathrm{cmm}$ were determined by relating the nucleated cell count to the white cell count.

For the quantitative determination of BAIB the urine $\stackrel{\mathbb{Q}}{\mathscr{2}}$ was measured and kept at $4^{\circ} \mathrm{C}$ and tested within 24 hours $\overrightarrow{\vec{\circ}}$ after the last collection. An aliquot of the 24-hour urine 3 collection was filtered and then used for electrophoresis without further treatment. The technique was that developed at the laboratory of Aglaia Kyriakou Hospital (Koniavitis, 1967), after adequate testing, for the purpose of this study. Twenty $\mu$ l of urine was applied in a narrow: band on a $31 \mathrm{~cm}$ long and $3 \mathrm{~cm}$ wide paper strip (SS 2043b/MG). Potassium hydrogen phthalate buffer at $p \mathrm{H} 4.3$ was used in the vessels $(5.1 \mathrm{ml}$ of the salt per litre adjusted with $2 \mathrm{~N} \mathrm{NaOH}$ ). A control strip with a standard solution of DL-beta-aminoisobutyric acid, ${ }^{1}$ at a concen-을 tration of $5 \mathrm{mg}$ per $100 \mathrm{ml}$, was always run in parallel. $)$ Electrophoresis lasted for one hour at 540 volts. After을 the run was completed the strips were dried at $120^{\circ} \mathrm{C}$ for 15 minutes and developed in a ninhydrin solution $(0.5 \mathrm{~g}$. in $100 \mathrm{ml}$ acetone) for five minutes followed by further $N$ drying at $90^{\circ} \mathrm{C}$ for 10 minutes. The zone of BAIB lay just cathodically to the band formed by glycine (Fig. 1).

Quantitative evaluation was carried out using an Analytrol scanner and the 24-hour excretion calculated.

The lowest concentration of BAIB added to normal $\mathbb{\Phi}$ urine which could be estimated with accuracy by this $\stackrel{\mathcal{P}}{+}$ method was $2.5 \mathrm{mg}$ per $100 \mathrm{ml}$. Amounts between 1 and 0 $2.5 \mathrm{mg}$ per $100 \mathrm{ml}$ were still detectable and are referred to as traces in Table $\mathrm{I}$; concentrations lower than $1 \mathrm{mg} \stackrel{\mathbb{\mathrm { D }}}{\Omega}$ were not visible on the strip.

${ }^{1}$ Obtained from Calbiochem in Europe, Loewengraben 14, $6002 \bar{\gamma}$ Luzezy, Switzerland. 


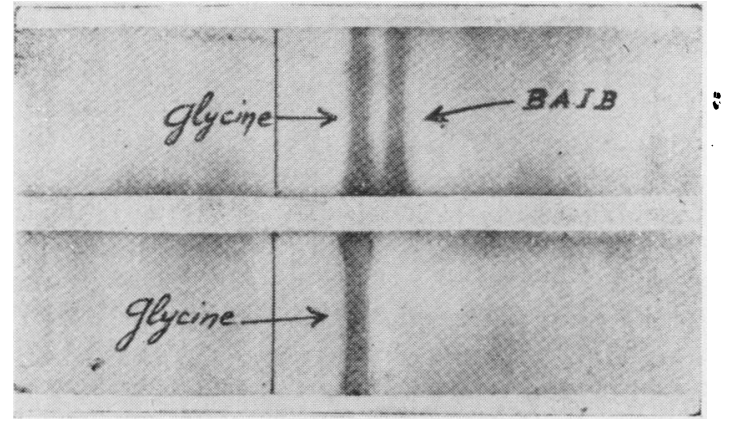

FIG. 1. The electrophoretic pattern of urine in a case of thalassaemia major (upper strip) and a normal control (lower strip). Ninhydrin stain. Cathode to the right.

\section{RESULTS}

The results are shown in Table I. No BAIB could be detected in the urine of either normal controls or simple thalassaemia heterozygotes. Constantly high excretion was observed in all non-splenectomized cases of thalassaemia major. Low to moderate excretion of BAIB was seen in all five cases of thalassaemia/HbS disease and in most cases of homozygous $\mathrm{HbS}$ disease. There was a low-grade excretion in a few cases of iron-deficiency anaemia.

In the non-splenectomized cases of thalassaemia major there was a steep decline in BAIB excretion immediately after transfusion. This was evident at 48 hours and continued for the next few days. Two weeks later the values were rising and after one month the initial pretransfusion values had been reached in most cases. The lowest level of excretion

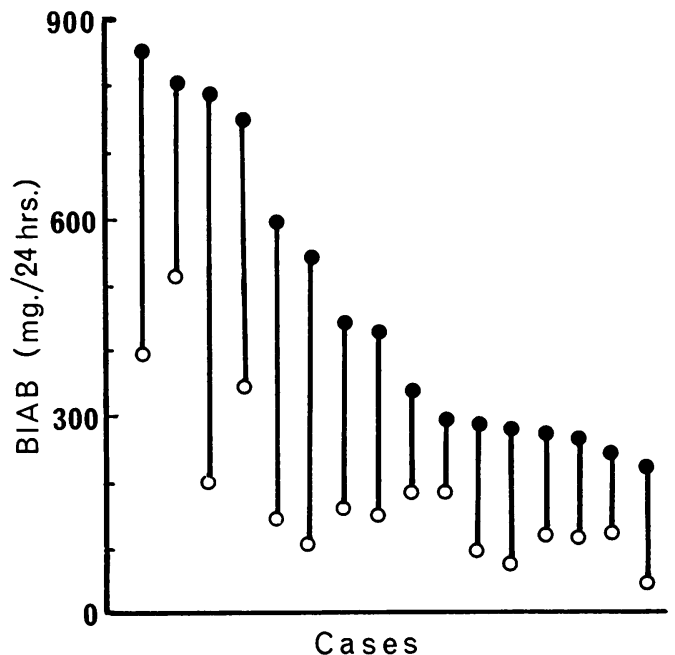

FIG. 2. The change of BAIB excretion in 16 cases of thalassaemia major before and after transfusion. Full circles $=$ immediate pretransfusion levels; open circles $=$ $48 \mathrm{hr}$ after transfusion.

reached, as determined at 48 hours, never fell to normal values. However, no patient was tested earlier than $\mathbf{4 8}$ hours and none had been transfused to a normal haemoglobin concentration. The pattern of excretion of BAIB following transfusion is shown in Figure 2. The excretion of BAIB appeared to be inversely proportional to the haemoglobin level (Fig. 3) and proportional to the number of normoblasts per $\mathrm{c} \mathrm{mm}$ of peripheral blood (Fig. 4).

Out of six cases of thalassaemia major that had been splenectomized long before this study, traces of BAIB were detected in five; in the sixth measurable

TABLE I

SUMMARY OF THE SERIES

Cases

$\begin{array}{llll}\begin{array}{l}\text { Number } \\ \text { of } \\ \text { Cases }\end{array} & \begin{array}{l}\text { Number } \\ \text { with BAIB } \\ \text { Excretion }\end{array} & \begin{array}{l}\text { Urinary BAIB }(\mathrm{mg} / 24 \mathrm{hr}) \\ \text { Before Transfusion }\end{array} & \frac{\text { After Transfusion }}{48 \text { Hours Eight Days } 15 \text { Days } 30 \text { Days }}\end{array}$

Normal controls

Thalassaemia major, non-splenectomized

Thalassaemia major, previously

splenectomized

Thalassaemia trait carriers

Sickle-cell anaemia

Sickle-cell thalassaemia

Iron-deficiency anaemia

Thalassaemia major, undergoing splenectomy

50
16
6
17
6
5
12

0
16
6
0
4
5
3

3

212-847
Trace-88
Trace-392
$37-224$
$48-63$

48-63

Before Splenectomy

\begin{tabular}{lll}
48 Hours Five Days Eight Days 12 Days \\
\hline
\end{tabular}




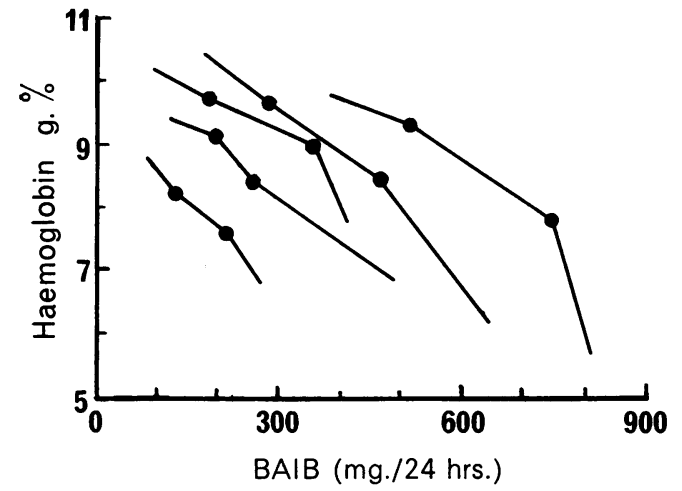

FIG. 3. Correlation between the haemoglobin level and $B A I B$ excretion in thalassaemia major following transfusion. Each line represents one case.

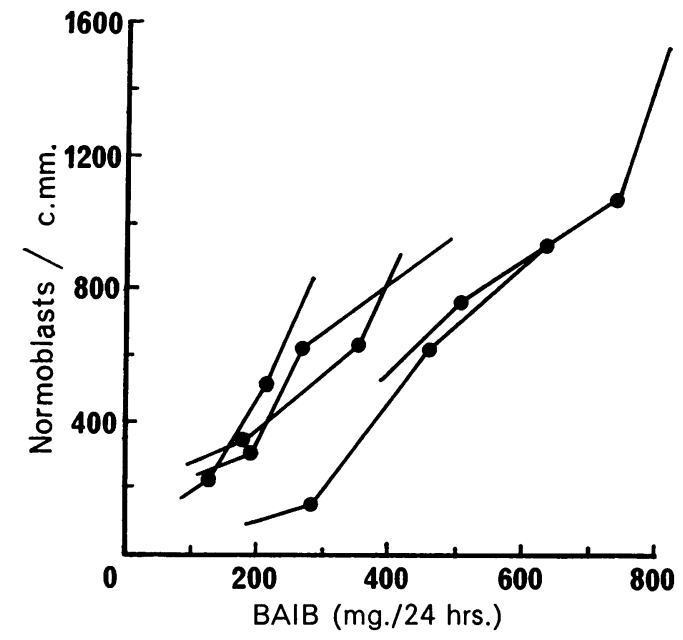

FIG. 4. Correlation between BAIB excretion and absolute number of circulating normoblasts in thalassaemia major. Each line represents one case.

amounts were present $(88 \mathrm{mg} / 24 \mathrm{hr})$, and these declined following transfusion. Only once in a case not included in this series was there a very high excretion $(660 \mathrm{mg} / 24 \mathrm{hr})$; the untimely death of this severely ill patient prevented further study, and permission for a postmortem examination, to investigate the presence of an accessory spleen, was not granted.

Three patients with thalassaemia major were studied soon after splenectomy. A brief rise over the preoperative values of BAIB, which were low in two cases because of transfusion, was observed $\mathbf{4 8}$ hours after the operation. This, however, was not sustained and trace values of BAIB were reached 12 days after the operation, although the number of circulating $\frac{\stackrel{0}{\vec{\sigma}}}{\underline{0}}$ normoblasts had increased strikingly.

All five cases of sickle-cell thalassaemia excreted $\overrightarrow{\vec{F}}$ BAIB at a level which was in general lower than that 0 observed in thalassaemia major. As a group they were less anaemic than the latter and also less $\frac{\bar{\sigma}}{\bar{D}}$ anaemic than those with iron-deficiency anaemia, in $\widehat{D}$ which excretion of BAIB was usually absent or, at most, insignificant. In one proven adult case of ${ }^{\infty}$ homozygous sickle cell disease, the amount of BAIB $\vec{\circ}$ was in the thalassaemia range, while in four children $\vec{\overrightarrow{ }}$ with probable sickle cell anaemia (exact genetic con- $\omega$ stitution unknown) the BAIB excretion ranged from 0 to $82 \mathrm{mg} / 24$ hours.

The three cases of iron-deficiency anaemia with BAIB-positive urine were the only ones in this group in which normoblasts were detected in the peripheral blood.

Since only the cases with thalassaemia major were $\stackrel{\text { 을 }}{-}$ tested repeatedly the possibility that some excretion 3 of BAIB might have been detected on other occasions cannot be excluded.

\section{DISCUSSION}

The present study confirms the findings of Hillcoat $O$ $(1960,1962)$ that large amounts of BAIB are found in the urine of patients with thalassaemia major but disappear with the removal of the spleen. The urinary

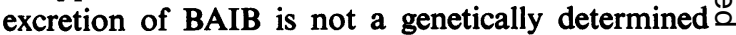
characteristic of thalassaemia since it was not ob- $\overrightarrow{\overrightarrow{0}}$ served in the parents of affected children; further- 3 more, excretion of BAIB was also observed in patients with other congenital or acquired anaemias.

Although the group of controls is limited, the failure to detect a high excretor among $\mathbf{5 0}$ healthy:individuals can be taken as evidence that hereditary 3 beta-aminoisobutyricaciduria is infrequent in the population being studied.

In contrast to the original reports on the excretion of BAIB in thalassaemia major, the present study appears to establish a negative correlation between the pattern of excretion and the level of haemoglobin and a positive correlation with the number of circu- $N$ lating normoblasts. It should be added, however, N that the same data indicate an inverse correlation between haemoglobin level and number of circulating ${ }_{\sigma}^{\omega}$ normoblasts.

The accepted explanation for the presence of BAIB in the urine of patients with thalassaemia major and of its absence after splenectomy is that ${ }^{+}$ thymine of erythroblastic origin is metabolized to $\frac{0}{\circ}$ this aminoacid in the spleen. Indeed, after the re- $\vec{\Phi}$ moval of the spleen, little or no excretion of BAIB $\frac{\rho}{1}$ is observed in spite of a manifold increase of the $\varrho$ number of circulating red cell precursors. Conversely? 
a spleen which is very effective in trapping and metabolizing the nuclei of normoblasts may lead to the excretion of large amounts of BAIB, while leaving only few nucleated cells in the circulation. Therefore no perfect correlation can be expected between the number of circulating normoblasts and excretion of BAIB, since such a comparison would ignore such factors as the size of the spleen, the efficiency of its pitting function, and the blood volume. On the other hand the correlation appears to be very satisfactory when values obtained at different times for the same case are compared.

The transitory rise in urinary BAIB, immediately after splenectomy, may be attributed to the surgical trauma (Levey and Woods, 1961).

As stated above, BAIB was detected, although in low concentrations, in other forms of hereditary anaemia, and in severe iron-deficiency anaemia. All cases studied had normoblasts in circulation. In none of these conditions, however, is there an erythroblastic hyperplasia comparable to that observed in the severe cases of thalassaemia included in this study. On the other hand in some of the cases of sickle-cell anaemia no BAIB was detected in the urine although the number of circulating normoblasts was in the range observed in thalassaemia major. The spleen was not palpable in these cases.
In thalassaemia relief of anaemia by transfusion led to a reduction of 50 to $75 \%$ in the excretion of BAIB compared with the immediate pre-transfusion levels. The reduction was of brief duration and was followed by higher values than anticipated from the fall in the haemoglobin level. No patient was transfused sufficiently to effect complete suppression of erythropoiesis, but it is reasonable to expect that the excretion of BAIB will disappear completely under such circumstances.

By taking into consideration all the evidence we conclude that the excretion of BAIB is a good index of the number of normoblast nuclei trapped and broken down in the spleen.

We are most grateful to Professor William Davidson, King's College Hospital, London, for his great assistance in revising our manuscript.

\section{REFERENCES}

Hillcoat, B. L. (1960). Aust. J. exp. Biol., 38, 441.

- (1962). Lancet, 1, 74.

Koniavitis, A. N. (1967). Theory and Practice of Laboratory Investigation (in Greek), Vol. A. Athens.

Levey, S., and Woods, T. (1961). Fed. Proc., $20,7$.

Sutton, H. E. (1960). In The Metabolic Basis of Inherited Disease, edited by J. B. Stanbury, J. B. Wyngaarden, and D. S. Fredrickson, p. 20. McGraw-Hill, New York. 